\title{
Adaptation of Soybean mosaic virus Avirulent Chimeras Containing P3 Sequences from Virulent Strains to Rsv1-Genotype Soybeans Is Mediated by Mutations in HC-Pro
}

\author{
M. R. Hajimorad, ${ }^{1}$ A. L. Eggenberger, ${ }^{2}$ and J. H. Hill ${ }^{2}$ \\ ${ }^{1}$ Department of Entomology and Plant Pathology, the University of Tennessee, Knoxville 37996, U.S.A.; ${ }^{2}$ Department \\ of Plant Pathology, lowa State University, Ames 50011, U.S.A.
}

Submitted 4 February 2008. Accepted 1 April 2008.

In Rsv1-genotype soybean, Soybean mosaic virus (SMV)-N (an avirulent isolate of strain G2) elicits extreme resistance (ER) whereas strain SMV-G7 provokes a lethal systemic hypersensitive response (LSHR). SMV-G7d, an experimentally evolved variant of SMV-G7, induces systemic mosaic. Thus, for Rsv1-genotype soybean, SMV-N is avirulent whereas SMV-G7 and SMV-G7d are both virulent. Exploiting these differential interactions, we recently mapped the elicitor functions of SMV provoking Rsv1mediated ER and LSHR to the N-terminal 271 amino acids of P3 from SMV-N and SMV-G7, respectively. The phenotype of both SMV-G7 and SMV-G7d were rendered avirulent on Rsv1-genotype soybean when the part of the genome encoding the $\mathbf{N}$-terminus or the entire $\mathbf{P 3}$ cistron was replaced with that from SMV-N; however, reciprocal exchanges did not confer virulence to SMV-N-derived P3 chimeras. Here, we describe virulent SMV-N-derived P3 chimeras containing the full-length or the N-terminal P3 from SMV-G7 or SMV-G7d, with or without additional mutations in P3, that were selected on Rsv1-genotype soybean by sequential transfers on $r s v 1$ and $R s v 1$-genotype soybean. Sequence analyses of the P3 and helper-component proteinase (HC-Pro) cistrons of progeny recovered from $R s v 1$-genotype soybean consistently revealed the presence of mutations in HC-Pro. Interestingly, the precise mutations in HC-Pro required for the adaptation varied among the chimeras. No mutation was detected in the $\mathrm{HC}$ Pro of progeny passaged continuously in rsv1-genotype soybean, suggesting that selection is a consequence of pressure imposed by Rsv1. Mutations in HC-Pro alone failed to confer virulence to SMV-N; however, reconstruction of mutations in HC-Pro of the SMV-N-derived P3 chimeras resulted in virulence. Taken together, the data suggest that HC-Pro complementation of P3 is essential for SMV virulence on Rsv1-genotype soybean.

Additional keywords: evolutionary experiments, experimental adaptation, Potyvirus

Corresponding author: M. R. Hajimorad; Fax: +1-865-974 4744; E-mail: mrh@utk.edu

* The $e$-Xtra logo stands for "electronic extra" and indicates a supplementary table and supplementary materials and methods information are published online.
One elaborate mechanism that plants have evolved to recognize and counterattack against invading pathogens, including viruses, involves resistance $(R)$ genes (Maule et al. 2007). The recognition mechanism operates based on a "gene-for-gene" hypothesis and is conditioned through matched specificity between products of an $R$ gene and a pathogen avirulence (Avr) gene, which is achieved by direct or indirect interactions (Bonas and Lahaya 2002; Dangl and Jones 2001; Flor 1971). Phenotypically, $R$-mediated recognition of plant viruses is expressed as extreme resistance (ER) or as a hypersensitive response (HR) (Hull 2002), both of which are assumed to be the consequence of the same recognition event (Bendahmane et al. 1999).

Pathogens have evolved means to evade $R$-mediated recognition or suppress the resistance response (Abramovitch et al. 2003; Jackson et al. 1999; Leach et al. 2001; Stahl and Bishop 2000; Tsiamis et al. 2000). Due to multifunctionality of viral gene products, minor modification of $A v r$ genes is the only affordable mechanism for evasion by plant viruses. $R$-dependent $A v r$ function for a number of plant viral genes has been established (Culver 1997) and comparison of their sequences with corresponding genes of virulent strains has shown only limited differences. Furthermore, in both HR- and ER-dependent pathosystems, exchange of such genes between avirulent and virulent strains has resulted in virulence of avirulent strains and vice versa, which suggests that virulence on $R$ genotype plants is associated with lack of the elicitor function (Culver 1997; Diveki et al. 2004; Karasawa et al. 1999; Kim and Palukaitis 1997; Kiraly et al. 1999; Malcuit et al. 1999; Padgett et al. 1997; Tsuda et al. 1998). Most of these studies, however, were conducted on viruses where functional proteins are expressed via single open reading frames (ORFs) (Hull 2002) but similar studies on pathosystems involving viruses with a polyprotein gene expression strategy, such as potyviruses, are limited (Hajimorad et al. 2005, 2006; Jenner et al. 2003).

Rsvl, a single dominant gene in soybean plant introduction (PI) line 96983 (Hayes et al. 2004), invokes ER following mechanical inoculation against most strains of Soybean mosaic virus (SMV), including SMV-N (an isolate of strain G2) but not SMV-G7 and its experimentally evolved variant, SMV-G7d (Cho and Goodman 1979; Hajimorad et al. 2003; Lim 1985). SMV-N induces Rsv1-mediated restricted systemic HR (SHR) if introduced into $R s v 1$ tissues from infected $r s v 1$ rootstocks or scions (Hajimorad and Hill 2001). In contrast, both SMV-G7 and SMV-G7d bypass Rsv1-mediated ER and spread systemically in 
PI 96983 (Rsv1) tissues where SMV-G7 provokes a lethal SHR (LSHR) and SMV-G7d induces systemic mosaic (Hajimorad et al. 2003). We have proposed earlier that Rsv1-mediated resistance operates based on two different mechanisms: primary resistance or ER (HR independent) is operational at the point of inoculation and secondary resistance (HR mediated) activates when the primary mechanism of resistance is bypassed and the HR elicitor is allowed to accumulate (Hajimorad and Hill 2001). Thus, we hypothesized that the SMV-N elicitor of ER and restricted SHR is the same virus protein, and that the corresponding region of SMV-G7, albeit modified, is also the elicitor of Rsv1-mediated LSHR (Hajimorad et al. 2005). By using SMVG7 and SMV-G7d, we mapped the SMV-G7 elicitor of Rsv1mediated LSHR to P3, and identified the amino acid residues involved (Hajimorad et al. 2005).

To test the possibility that the SMV elicitor of both Rsv1mediated LSHR and ER are modified forms of P3, we also exploited the differential interactions of SMV-N, SMV-G7, and SMV-G7d with Rsv1-genotype soybean and replaced precisely the N-terminus or the entire P3 of SMV-G7 or SMVG7d with that of SMV-N and vice versa (Hajimorad et al. 2006). Inoculation of the chimeras on Rsvl-genotype soybean showed that all SMV-G7 and SMV-G7d-derived P3 chimeras lost virulence on Rsv1-genotype soybean; however, surprisingly, SMV-N-derived P3 chimeras remained avirulent (Hajimorad et al. 2006).

To identify virulent or avirulent determinants of plant viruses, virologists have traditionally exploited differential interactions of viral strains with $R$-genotype plants (Culver 1997; Karasawa et al. 1999; Kim and Palukaitis 1997; Kiraly et al. 1999; Malcuit et al. 1999; Padgett et al. 1997; Tsuda et al. 1998). In this study, however, we have taken advantage of error-prone replication of RNA viruses (Drake and Holland 1999; Steinhauer et al. 1992) combined with positive selection pressure driven by $R$ genes (Garcia-Arenal et al. 2001) and searched for the genetic determi- nants essential for converting avirulent pSMV-N-derived P3 chimeras to virulent on $R s v 1$-genotype soybean. In this report, we show that sequential transfer of progenies from avirulent SMV$\mathrm{N}$-derived P3 chimeras, with or without additional mutations in $\mathrm{P} 3$, on $r s v 1$ - and Rsv l-soybean genotypes, resulted in adaptation to Rsvl-genotype soybean. Additionally, we demonstrate that the adaptations of the progenies are associated with mutations in helper-component proteinase (HC-Pro), and present direct evidence that HC-Pro mutations are essential and sufficient for virulence of the pSMV-N-derived P3-chimeric viruses on Rsv1genotype soybean. The results demonstrate that evolutionary experiments have the potential to be used as an alternative approach to comparative studies in revealing virulence determinants of plant viruses.

\section{RESULTS}

\section{Passage of progenies from pSMV-N-derived P3 chimeras in William $82(r s v 1)$ results} in gain of virulence on Rsv1-genotype soybean.

All pSMV-N-derived chimeras containing P3 sequences from pSMV-G7 and pSMV-G7d (Hajimorad et al. 2006) were replication competent when biolistically delivered onto hypocotyls of Williams 82 ( $r s v 1)$ (Fig. 1). Biolististic inoculation of pSMV-N-derived P3 chimeras containing mutations in P3

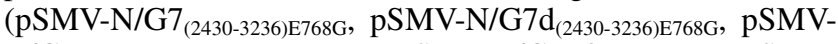
N/G7 (2430-3236)E768G+V996A, pSMV-N/G7P3 $_{\text {E768G, }}$ pSMV$\mathrm{N} / \mathrm{G} 7 \mathrm{dP} 3_{\mathrm{E} 768 \mathrm{G}}$, and $\left.\mathrm{pSMV}-\mathrm{N} / \mathrm{G} 7 \mathrm{P} 3_{\mathrm{E} 768 \mathrm{G}+\mathrm{V} 996 \mathrm{~A}}\right)$ also resulted in infection of 80 to $100 \%$ of inoculated Williams 82 ( $r s v 1$ ). However, none of the chimeras, with or without mutations in P3, were virulent when similarly inoculated to PI 96983 (Rsvl) hypocotyls (Fig. 1; data not shown). Mechanical inoculation of progenies passaged in William 82 ( $r s v 1$ ) to L78-379 $(R s v 1)$, which is a near isoline of Williams with the Rsv1 allele derived from PI 96983 (Buzzell and Tu 1984), also failed to

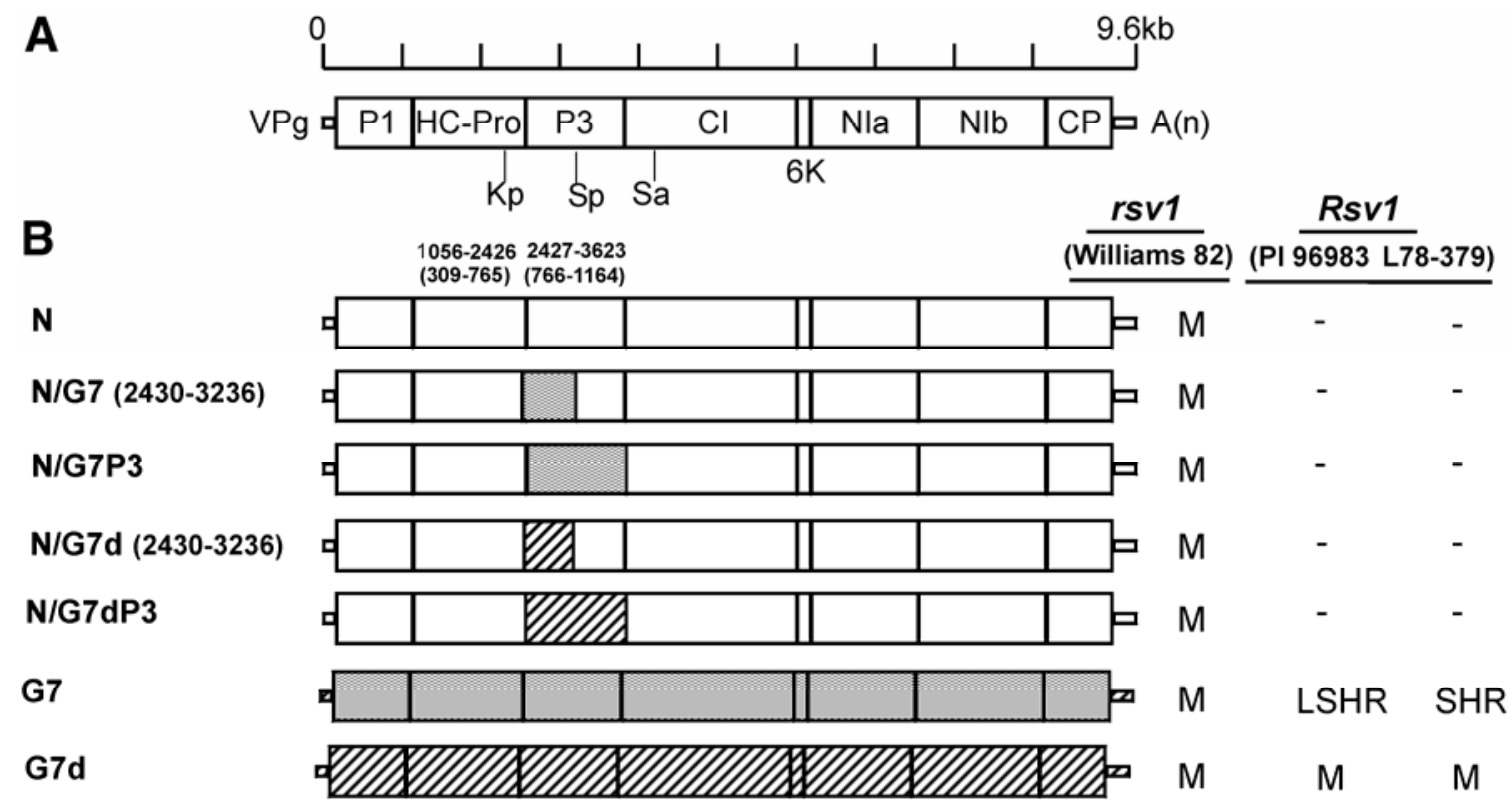

Fig. 1. A, Schematic representation of the genome of Soybean mosaic virus (SMV) showing the position of the unique restriction sites KpnI (Kp), SpeI (Sp), and SalI (Sa). B, Schematic representation of molecularly cloned parental viruses pSMV-N (N), pSMV-G7 (G7), pSMV-G7d (G7d), and pSMV-N (N)derived P3 chimeras containing the full-length or N-terminus of P3 from G7 or G7d (Hajimorad et al. 2005, 2006). The locations of helper-component proteinase (HC-Pro) and P3 cistrons in the 9.6-kb SMV-N genome are shown along with the amino acid positions in parentheses. Note that in the genomes of SMV-G7 and SMV-G7d, the genomic positions of HC-Pro and P3 differ by 3 nucleotides, because SMV-N lacks a codon in the P1 region (GenBank accession numbers AY216010, AY216987, and D00507, respectively). Responses of Williams 82 (rsv1) and PI 96983 (Rsv1) to biolistic inoculation with infectious cDNAs and L78-379 (Rsv1) to mechanical inoculation with progenies of cloned viruses derived from Williams 82 ( $r s v 1)$ are indicated. Plants were evaluated visually for the presence of symptoms (mosaic $=\mathrm{M}$, systemic hypersensitive response $=\mathrm{SHR}$, lethal SHR $=\mathrm{LSHR}$ ) or absence of infection $(-)$ by squash immunoblotting 4 weeks postinoculation. 
infect any of the inoculated plants (Figs. 1 to 3). Lack of virulence on L78-379 (Rsvl) was regardless of the number of passages of progenies in Williams $82(r s v 1)$.

However, passages of progenies in Williams 82 ( $r s v 1)$ and subsequent mechanical inoculation to PI 96983 (Rsvl) and L78-379 (Rsvl) occasionally yielded infection in a few of the inoculated PI 96983 (Rsvl). For example, in the experiments resulting in adaptation of progenies from pSMV-N/G7P3 and pSMV-N/G7 $7_{(2430-3236)}$ to PI $96983(R s v 1)$, only one of 26 and three of 31 of the inoculated plants became infected, respectively (Fig. 2). However, co-inoculation of more than 25 L78379 (Rsv1) with progenies derived from each of the two chimeras did not induce infection in any of the inoculated plants. The number of passages of progenies in Williams 82 ( $r s v 1)$ required for adaptation to PI 96983 (Rsvl) varied among the chimeras. Symptoms of infection in the infected Rsvl-genotype soybean generally appeared late ( 3 to 4 weeks postinoculation) and progressed slowly from lower to upper parts of the infected plants. Passages of progenies in PI 96983 (Rsv1), however, enhanced the virulence of progenies on Rsvl-genotype soybean because more of the inoculated PI 96983 (Rsvl) became infected in the second passage. For example, when progenies derived from pSMV-N/G7P3 and pSMV-N/G7dP3 were adapted to PI 96983 (Rsvl), passaged twice in the same genotype, and used as inoculums, five of 25 and 13 of 13 inoculated PI 96983 (Rsv1) became infected, respectively. Furthermore, symptoms appeared faster and progressed more quickly compared with those induced by the first passage of progenies in the same soybean genotype. Passages of progenies in PI $96983(R s v 1)$ resulted in gain of virulence on L78-379 (Rsvl) (Figs. 2 to 4). Analysis of the P3 sequences recovered from rsvl-and Rsvl-genotype soybean showed complete identity with the parental chimeras (Figs. 2 and 3 ).

Progenies from pSMV-N/G7 $\mathrm{d}_{(2430-3236)}$ and pSMV-N/G7dP3 containing a single mutation in $\mathrm{P} 3$ proximal to the $5^{\prime}$ end $(\mathrm{E} 768 \mathrm{G})\left(\mathrm{pSMV}-\mathrm{N} / \mathrm{G} 7 \mathrm{~d}_{(2430-3236) \mathrm{E} 768 \mathrm{G}}\right.$ and $\left.\mathrm{pSMV-N} / \mathrm{G} 7 \mathrm{dP} 3_{\mathrm{E} 768 \mathrm{G}}\right)$ gained virulence on PI 96983 (Rsv1) following only a single passage in Williams 82 ( $r s v 1)$ (Fig. 3B and C). Inoculation of progenies of pSMV-N/G7 $\mathrm{d}_{(2430-3236) \mathrm{E} 768 \mathrm{G}}$ and $\mathrm{pSMV}$ $\mathrm{N} / \mathrm{G} 7 \mathrm{dP} 3_{\mathrm{E} 768 \mathrm{G}}$ derived from the first passage in Williams 82 to PI $96983(R s v 1)$ resulted in four of 20 and three of 20 of the inoculated plants, respectively. Nevertheless, the progenies were avirulent on L78-379 (Rsv1) (Fig. 3) because none of 29 and 32 L78-379 (Rsv1) inoculated with similar inoculums derived from Williams 82-infected $\mathrm{pSMV-N} / \mathrm{G} 7 \mathrm{~d}_{(2430-3236) \mathrm{E} 768 \mathrm{G}}$ and $\mathrm{pSMV}-\mathrm{N} / \mathrm{G} 7 \mathrm{dP} 3_{\mathrm{E} 768 \mathrm{G}}$ became infected. Additional passages of progenies in PI $96983(R s v 1)$ resulted in gain of virulence on L78-379 (Rsvl) (Fig. 3B and C). The P3 sequences of progenies of $\mathrm{pSMV}-\mathrm{N} / \mathrm{G} 7 \mathrm{dP} 3_{\mathrm{E} 768 \mathrm{G}}$ from $r s v 1$ - and $R s v 1$-genotype soybean were identical to those of the parental chimeras (Fig. $3 \mathrm{~B}$ and $\mathrm{C})$. The $\mathrm{P} 3$ of progenies from $\mathrm{pSMV}-\mathrm{N} / \mathrm{G} 7 \mathrm{~d}_{(2430-3236) \mathrm{E} 768 \mathrm{G}}$ recovered from Williams $82(r s v l)$ was identical to the parental plasmid, but those from PI 96983 (Rsv1) and L78-379 (Rsvl) contained a single mutation (F1153I) (Fig. 3C).
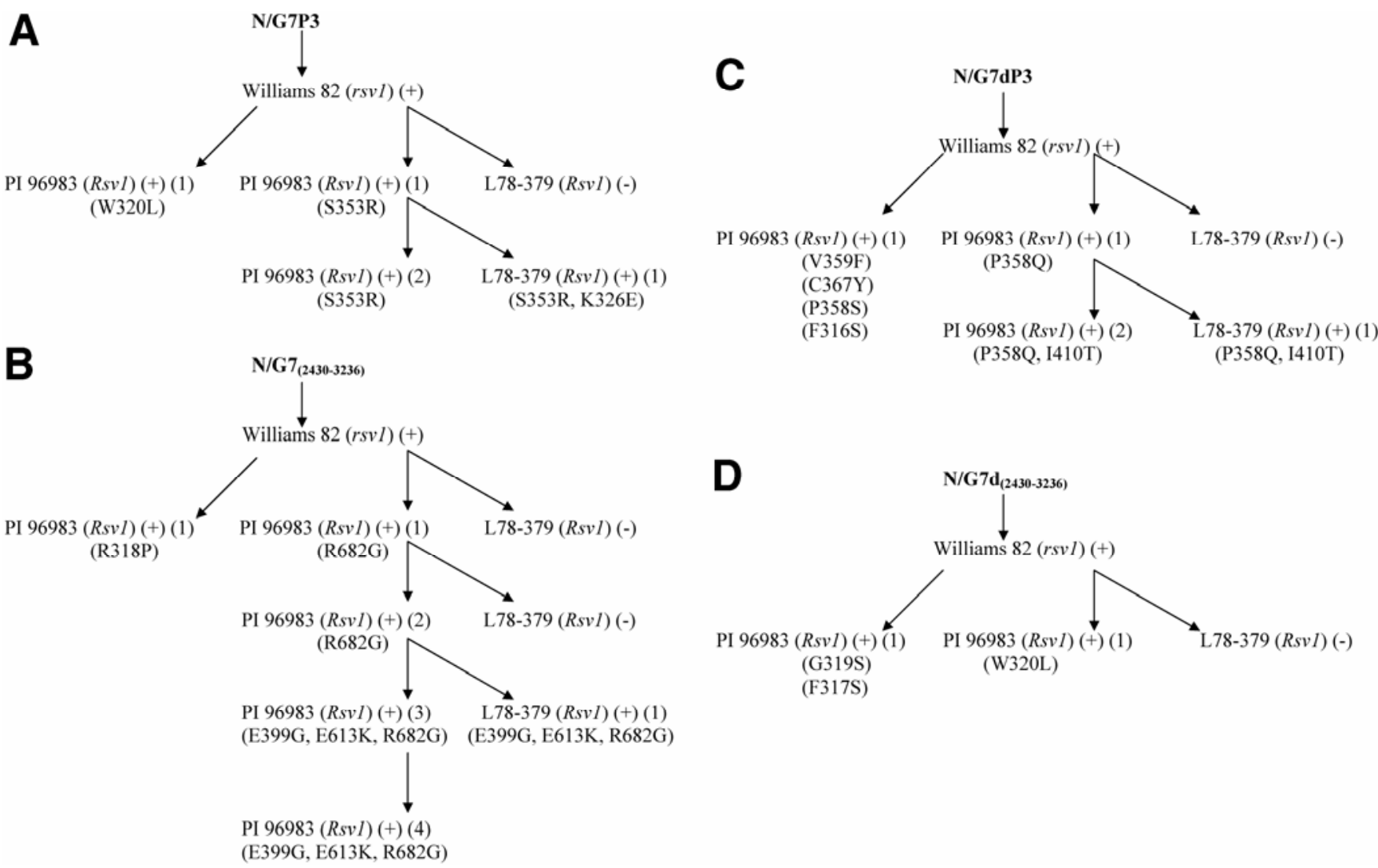

Fig. 2. Adaptations of progenies from Soybean mosaic virus (pSMV)-N derived P3-chimeras to Rsv1-genotype soybean and associated mutations in helpercomponent proteinase (HC-Pro). A-D, Hypocotyls of Williams 82 ( $r s v 1$ ) were biolistically inoculated with infectious cDNAs of chimeras. Progenies passaged in Williams 82 (rsvl) were mechanically inoculated to plant introduction (PI) 96983 (Rsv1) and L78-379 (Rsv1). Note that the number of passages of progenies in Williams 82 ( $r s v 1$ ) required for adaptation to PI 96983 (Rsv1) varied among the chimeras. Progenies from one of the infected PI 96983 (Rsv1) plants were subsequently inoculated to Rsvl-genotype soybean. Symbols in parentheses to the right of each soybean line indicate the soybean genotype, presence $(+)$ or absence $(-)$ of virus as detected by squash immunoblotting or double-antibody sandwich enzyme-linked immunosorbent assay, and the number of consecutive passages in the designated soybean line, respectively. The presence of mutations, all within HC-Pro, was determined by direct sequencing of reverse-transcriptase polymerase chain reaction products containing the HC-Pro and P3 cistrons. The locations of mutations are shown in parentheses below each of the Rsvl-genotype soybean. 


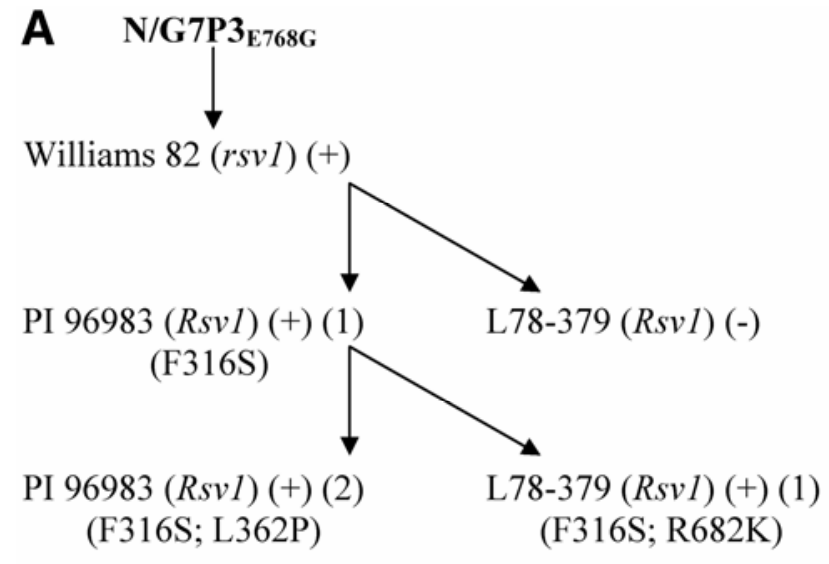

B $\quad$ N/G7dP3 E768G

Williams $82(r s v l)(+)$

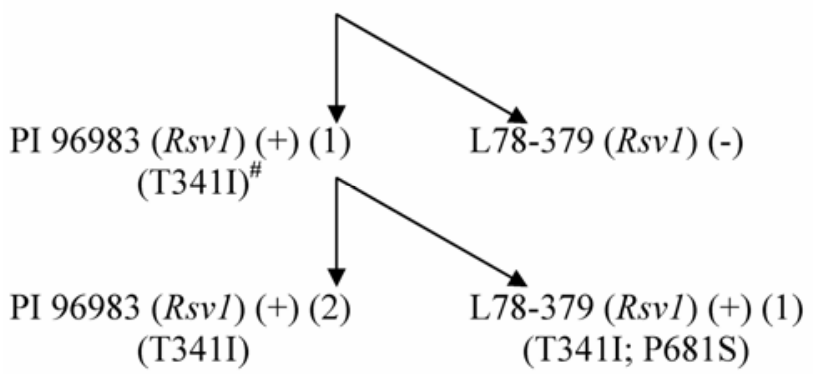

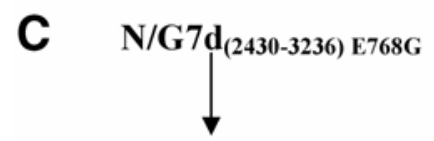

Williams $82(r s v l)(+)$
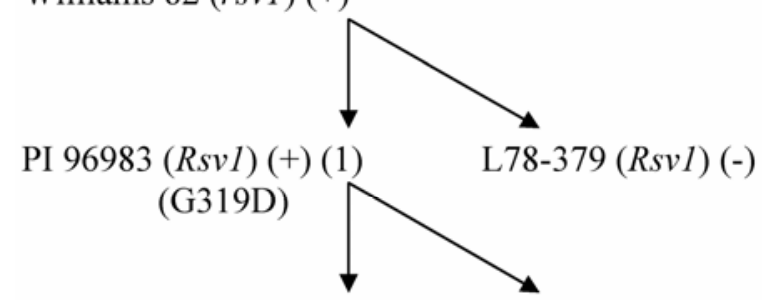

PI $96983(R s v l)(+)(2)$

(G319D; F1153I*)

L78-379 (Rsv1) (+) (1)

(G319D; S355L; F1153I*)

Fig. 3. Adaptations of progenies from Soybean mosaic virus (pSMV)-Nderived P3 chimeras containing a single mutation in 5' proximal P3 (E768G) to $R s v 1$-genotype soybean and associated mutations in helper-component proteinase (HC-Pro) and P3. A through C, Hypocotyls of Williams 82 ( $r s v l)$ were biolistically inoculated with infectious cDNAs of the chimeras. Progenies passaged in Williams $82(r s v)$ were mechanically inoculated to plant introduction (PI) 96983 (Rsv1) and L78-379 (Rsv1). Progenies from one of the infected PI 96983 (Rsv1) were subsequently mechanically inoculated to Rsv1-genotype soybean. Symbols in parentheses to the right of each soybean line indicate soybean genotype, presence $(+)$ or absence $(-)$ of virus as detected by squash immunoblotting or double-antibody sandwich enzymelinked immunosorbent assay, and the number of consecutive passages in the designated soybean line, respectively. The presence of mutations, all within HC-Pro except for the mutation designated by an asterisk (*), were determined by direct sequencing of reverse-transcriptase polymerase chain reaction products containing the HC-Pro and $\mathrm{P} 3$ cistrons. The locations of mutations are shown in parentheses below each of the Rsv1-genotype soybean; \# indicates a polymorphism at this location as both threonine and isoleucine are encoded.
Surprisingly, passages of progenies from pSMV-N-derived avirulent chimeras containing P3 sequences from SMV-G7, but with additional mutations (pSMV-N/G7 (2430-3236)E768G, $_{\text {, }}$

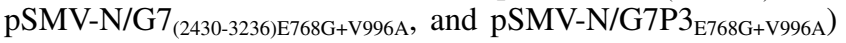
in Williams $82(r s v 1)$, did not result in gain of virulence on PI $96983(R s v 1)$ or L78-379 (Rsv1). P3 of progenies recovered

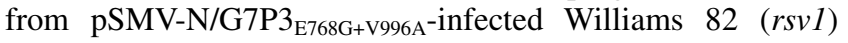
was identical to that of the parental plasmid. However, the P3

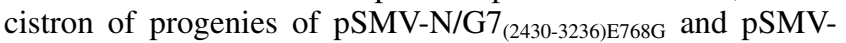
$\mathrm{N} / \mathrm{G} 7_{(2430-3236) \mathrm{E} 768 \mathrm{G}+\mathrm{V} 996 \mathrm{~A}}$ from Williams 82 ( $\left.r s v 1\right)$ contained silent mutations at locations 2,768 (C to A) and 2,675 (A to $\mathrm{G}$ ), respectively.

\section{Mutations in P3 of pSMV-N-derived chimeras alone do not influence virulence on $R s v 1$-genotype soybean.}

Progenies from $\mathrm{pSMV}-\mathrm{N} / \mathrm{G} 7 \mathrm{dP} 3_{\mathrm{E} 768 \mathrm{G}}$ and $\mathrm{pSMV}-\mathrm{N} / \mathrm{G} 7 \mathrm{~d}_{(2430-}$ 3236)E768G adapted quickly to $R s v 1$-genotype soybean; therefore, we hypothesized that additional manipulation of P3 would confer virulence to pSMV-N-derived P3 chimeras on Rsv1genotype soybean without a need for passage in Williams 82 $(r s v l)$. To study this possibility, we targeted amino acid at location 915 in P3 derived from pSMV-G7d. The codon at this location in the genomes of pSMV-G7 (the progenitor of pSMV-G7d) and vSMV-G7d, the parental virus population from which pSMV-G7d was derived, codes for methionine, but that of pSMV-G7d encodes valine (Hajimorad et al. 2003). Unlike vSMV-G7d and pSMV-G7d $\mathrm{v}_{\mathrm{V} 915 \mathrm{M}}$, infection of PI 96983 $(R s v 1)$ by pSMV-G7d is occasionally associated with a mild necrosis on the first trifoliolate leaves (M. R. Hajimorad, unpublished data). To examine the possibility that V915M substitution in the genomes of pSMV-N/G7dP3 and pSMV$\mathrm{N} / \mathrm{G} 7 \mathrm{dP} 3_{\mathrm{E} 768 \mathrm{G}}$ may confer virulence on Rsv1-genotype, $\mathrm{pSMV}-\mathrm{N} / \mathrm{G} 7 \mathrm{dP} 3_{\mathrm{V} 915 \mathrm{M}}$ and $\mathrm{pSMV}-\mathrm{N} / \mathrm{G} 7 \mathrm{dP} 3_{\mathrm{E} 768 \mathrm{G}+\mathrm{V} 915 \mathrm{M}}$ were constructed. Both the chimeras were replication competent in Williams 82 ( $r s v 1)$ when biolistically inoculated but remained avirulent on PI 96983 (Rsv1). Mechanical inoculation of progenies of pSMV-N/G7dP3 $3_{\mathrm{V} 915 \mathrm{M}}$ and $\mathrm{pSMV-N/G7dP} 3_{\mathrm{E} 768 \mathrm{G}+\mathrm{V} 915 \mathrm{M}}$ from Williams $82(r s v 1)$ to PI $96983(R s v 1)$ and L78-379 $(R s v 1)$ resulted in infection in three of 23 and one of 32 inoculated PI $96983(R s v 1)$, respectively, but none of 40 inoculated L78-379 (Rsv1). Additional passages of progenies from $\mathrm{pSMV-N/G7dP3} 3_{\mathrm{E} 768 \mathrm{G}+\mathrm{V} 915 \mathrm{M}}$ in PI $96983(R s v 1)$ resulted in enhancement of virulence as 13 of 14 inoculated PI 96983 (Rsv1) became infected.

We also examined the impact of E767G and E768G substitutions on virulence of SMV-N (E767G) and SMV-G7 (E768G) and SMV-G7d (E768G) on Rsv1-genotype soybean (note that the genomic position of this amino acid on SMV-N differs from that of SMV-G7 and SMV-G7d, because SMV-N lacks a codon relative to SMV-G7 and SMV-G7d in the P1 region). The same mutation was also introduced into pSMV$\mathrm{N}_{\mathrm{V} 822 \mathrm{M}+\mathrm{K} 952 \mathrm{E}+\mathrm{A} 1111 \mathrm{~V}}$ (Hajimorad et al. 2006). When inoculated biolistically, both pSMV-G7 $\mathrm{d}_{\mathrm{E} 768 \mathrm{G}}$ and $\mathrm{pSMV-G7} 7_{\mathrm{E} 768 \mathrm{G}}$ were

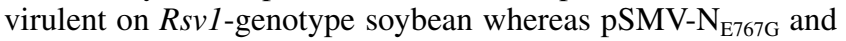
pSMV-N $\mathrm{E}_{\mathrm{E} 767 \mathrm{G}+\mathrm{V} 822 \mathrm{M}+\mathrm{K} 952 \mathrm{E}+\mathrm{A} 1111 \mathrm{~V}}$ remained avirulent. All the mutants remained replication competent in Williams 82 ( $r s v 1)$ (data not shown).

\section{Mutation in HC-Pro is associated with adaptations of progenies derived from the avirulent} pSMV-N-derived P3 chimeras to Rsv1-genotype soybean.

Because no mutation in P3 was associated with the adaptation of progenies from pSMV-N-derived P3 chimeras to Rsv1genotype soybean, additional efforts focused on the multifunctional HC-Pro (Urcuqui-Inchima et al. 2001). The full-length HC-Pro cistron of progenies from all chimeras from $r s v 1$ - and $R s v 1$-genotype soybean were recovered, sequenced, and ana- 
lyzed. No mutations were detected in the HC-Pro cistrons of any progenies from Williams 82 (rsvl) (Figs. 2 to 5). However, progenies from PI $96983(R s v 1)$ and L78-379 (Rsvl) consistently showed the presence of mutations (Figs. 2 to 5). Mutations detected in the first passage of progenies in PI 96983 $(R s v l)$ were also detected in the second passage and were present in HC-Pro of progenies from L78-379 (Rsv1) (Figs. 2 to $5)$. Occasionally, the number of mutations in HC-Pro of the progenies increased upon additional passages in PI 96983 (Rsvl) (Figs. 2 to 5). Interestingly, virulence of progenies on L78-379 (Rsv1) was consistently associated with an additional mutation in HC-Pro compared with progenies from PI 96983 (Rsvl) (Figs. 2 to 4). The majority of the HC-Pro mutations were unique to progenies of a particular chimera (Figs. 2 and 3 ). However, different mutations in HC-Pro were found associated with the adaptation of progenies of the same chimera to PI 96983 (Rsv1) (Fig. 2). Progenies of pSMV-N/G7P3 isolated from two different trifoliate leaves of a single infected PI 96983 (Rsvl) had the same mutation in HC-Pro (W320L).

\section{Mutations in HC-Pro alone do not confer virulence to $\mathrm{pSMV}$-N on PI 96983 (Rsv1).}

To study the possibility that mutation in only HC-Pro converts avirulent pSMV-N to virulent on $R s v 1$-genotype soybean, 11 identified mutations were reconstructed into HC-Pro of pSMV-N (Table 1). All of these mutations, except K326E and R682K, were associated with the adaptation of progenies from pSMV-N-derived P3 chimeras to PI 96983 (Rsvl) and were identified in the first passage (Figs. 2 and 3). The mutations $\mathrm{K} 326 \mathrm{E}$ and $\mathrm{R} 682 \mathrm{~K}$ were identified in $\mathrm{P} 3$ of progenies from the

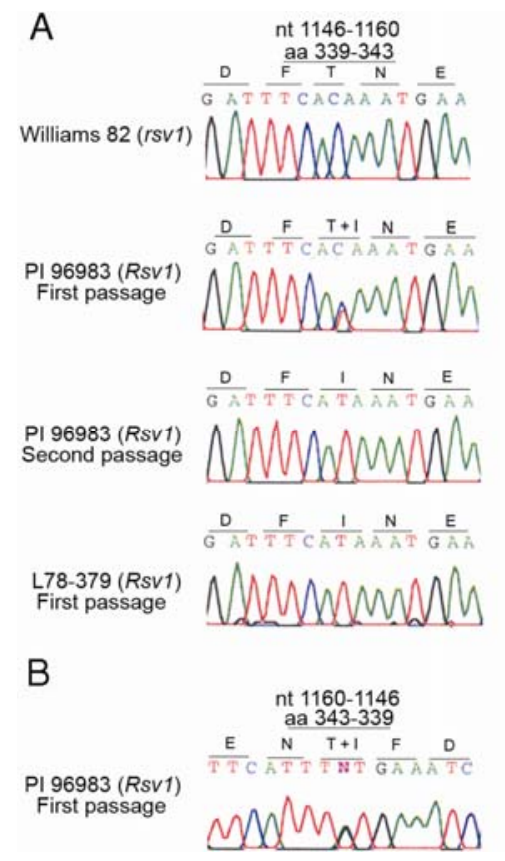

Fig. 4. A, Electropherograms showing the sequences of reverse-transcriptase polymerase chain reaction (RT-PCR) products from progenies derived from Soybean mosaic virus (pSMV)-N/G7dP3 $3_{\mathrm{E} 768 \mathrm{G}}$. The helper-component proteinase (HC-Pro) sequences shown were generated using a forward primer. Encoded SMV-N amino acids and their locations within the HC-Pro cistron are shown above and soybean genotypes on the left side of the electropherograms. Note the polymorphism at nucleotide 1,153 in the sequence from the first passage in plant introduction (PI) 96983 (Rsv 1 ) and fixation of the mutation in the second passage in PI 96983 (Rsv1) as well as an additional mutation that is associated with the first passage of progenies in L78-379 (Rsv1). B, Electropherogram showing the sequences of an RT-PCR product from the first passage in PI $96983(R s v 1)$ generated with a reverse primer to demonstrate that the sequence polymorphism in A is not a sequencing artifact. first passage in L78-379 (Rsv1) (Figs. 2A and 3A, respectively). When hypocotyls of Williams 82 ( $r s v 1)$ were biolistically inoculated, all of the pSMV-N-derived HC-Pro-mutants were replication competent; however, none of those tested was virulent on PI 96983 (Rsvl) (Table 1). Similar results were obtained when progenies from pSMV-N-derived HC-Pro mutants passaged in Williams 82 ( $r s v 1)$ were inoculated to PI 96983 (Rsv1) (Table 1). These observations suggest that HC-Pro mutation alone is incapable of rendering avirulent pSMV-N to a virulent virus on $R s v 1$-genotype soybean.

\section{The pSMV-N-derived P3 chimeras containing a single mutation in HC-Pro are virulent on PI 96983 (Rsv1).}

To provide evidence that a single mutation in HC-Pro can confer virulence to the pSMV-N-derived avirulent P3 chimeras on $R s v 1$-genotype soybean, 11 of the identified mutations from the first passage of the progenies in PI 96983 (Rsvl) and L78379 (Rsvl) were reconstructed into the infectious cDNAs of the avirulent chimeric viruses (Table 2). Each of the chimeras with a single mutation in HC-Pro was biolistically inoculated onto expanded unifoliate leaves of PI 96983 (Rsvl) and Williams $82(r s v 1)$. All the chimeras except $\mathrm{pSMV}-\mathrm{N}_{\mathrm{K} 326 \mathrm{E}} / \mathrm{G} 7 \mathrm{P} 3$,
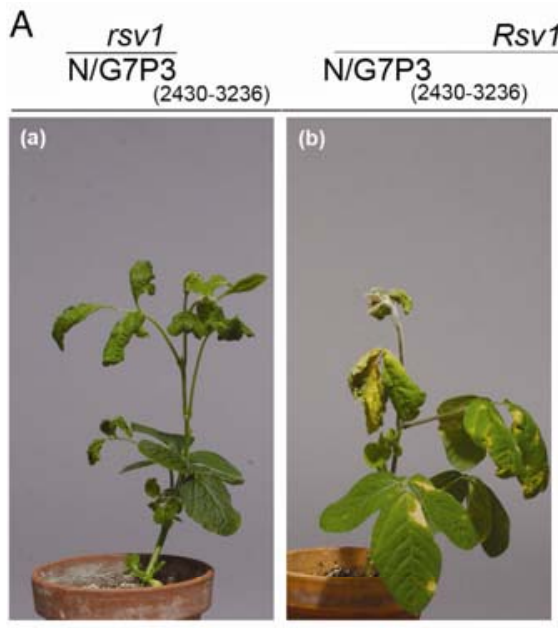

\section{N/G7P3}

B
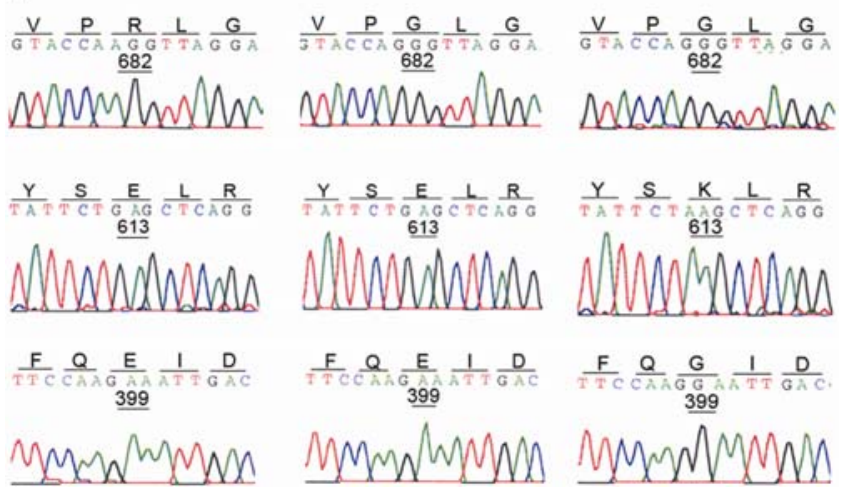

Fig. 5. A, Phenotypes of N/G7P $3_{(2430-3236)}$ on (a) Williams 82 (rsvl) or (b and c) plant introduction (PI) 96983 (Rsvl) following (a) biolistic inoculation with infectious cDNA or (b and $\mathbf{c}$ ) mechanical inoculation of passaged progenies. Progenies passaged in Williams 82 ( $r s v 1)$ were mechanically inoculated to PI 96983 (Rsvl). Progenies derived from one of the infected PI 96983 (Rsv1) was inoculated to (b). Infectious sap from (b) was subsequently inoculated to (c). Thus, (b) and (c) represent the second and the third passages of the progenies in PI 96983 (Rsv1), respectively. B, Electropherograms of sequences of reverse-transcriptase polymerase chain reaction products from progeny viruses flanking codons 399, 613, and 682 within the helper-component proteinase (HC-Pro) cistron. 


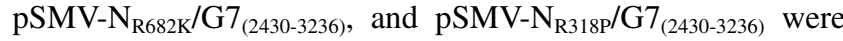
virulent on PI 96983 (Rsv1) (Table 2). However, all were replication competent in Williams 82 ( $r s v 1)$ (Table 2). Analyses of the full-length sequences of P3 and HC-Pro of progenies recovered from PI 96983 (Rsvl) showed the lack of any new mutation in both cistrons. Sequence analyses of the P3 and HCPro cistrons of progenies derived from pSMV-N $\mathrm{K}_{\mathrm{K} 26 \mathrm{E}} / \mathrm{G} 7 \mathrm{P} 3-$, $\mathrm{pSMV-N} \mathrm{R} 682 \mathrm{~K} / \mathrm{G}_{(2430-3236)^{-}}$, and $\mathrm{pSMV} \mathrm{N}_{\mathrm{R} 318 \mathrm{P}} / \mathrm{G}_{(2430-3236)^{-}}$ infected Williams-82 ( $r s v 1)$ also showed the absence of any new mutation in the two cistrons.

\section{DISCUSSION}

In the search for the genetic determinants essential for converting avirulent pSMV-N-derived P3 chimeras to virulent on Rsvl-genotype soybean, we utilized an experimental evolutionary approach and took advantage of the error-prone replication of RNA viruses combined with positive selection pressure imposed by $R$ genes. This contrasts with the more traditional comparative approach of identifying viral virulence determinants (Culver 1997; Karasawa et al. 1999; Kim and Palukaitis 1997; Kiraly et al. 1999; Malcuit et al. 1999; Padgett et al. 1997; Tsuda et al. 1998). In our previous studies, we have also used a comparative approach in identifying P3 as the elicitor of Rsv1-mediated LSHR and ER (Hajimorad et al. 2005, 2006). In those experiments, replacement of $P 3$ sequences of pSMV-G7 and pSMV-G7d with that of pSMV-N rendered both viruses avirulent on Rsv1-genotype soybean but, to our surprise, reciprocal exchanges did not result in gain of virulence of pSMV-N-derived P3 chimeras (Hajimorad et al. 2006). This suggested to us that, in addition to P3, genetic determinants residing elsewhere on the genomes of SMV-G7 and SMV-G7d also contribute to the virulence on Rsvl-genotype soybean (Hajimorad et al. 2006).

In this report, we have shown that passages of progenies from pSMV-N-derived $\mathrm{P} 3$ chimeras, with or without mutations in P3, in Williams 82 ( $r s v 1)$ followed by inoculation to PI 96983 (Rsvl) resulted in adaptation to Rsv1-genotype soybean. P3 sequences of all the progenies from $R s v 1$-genotype soybean,

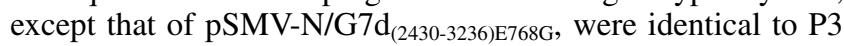
of the parental chimeric viruses. Conversely, mutations were consistently detected in the HC-Pro cistrons of progenies of all

Table 1. Responses of soybean genotypes Williams $82(r s v 1)$ and plant introduction (PI) 96983 (Rsv1) to inoculation with Soybean mosaic virus (pSMV)-N-derived helper-component proteinase (HC-Pro) mutants ${ }^{\mathrm{a}}$

\begin{tabular}{|c|c|c|c|c|}
\hline \multirow[b]{2}{*}{ Mutants } & \multicolumn{2}{|c|}{ Biolistic inoculation $^{\text {b }}$} & \multicolumn{2}{|c|}{ Mechanical inoculation } \\
\hline & Williams 82 & PI 96983 & Williams 82 & PI96983 \\
\hline pSMV-N ${ }_{\mathrm{K} 326 \mathrm{E}}$ & + & ND & + & - \\
\hline pSMV-N ${ }_{W 320 L}$ & + & ND & + & - \\
\hline $\mathrm{pSMV}-\mathrm{N}_{\mathrm{R} 682 \mathrm{G}}$ & + & - & + & - \\
\hline $\mathrm{pSMV}-\mathrm{N}_{\mathrm{R} 682 \mathrm{~K}}$ & + & - & + & - \\
\hline $\mathrm{pSMV}-\mathrm{N}_{\mathrm{R} 318 \mathrm{P}}$ & + & - & + & - \\
\hline pSMV-N & + & ND & + & - \\
\hline $\mathrm{pSMV}-\mathrm{N}_{\mathrm{V} 359 \mathrm{~F}}$ & + & ND & + & - \\
\hline $\mathrm{pSMV}-\mathrm{N}_{\mathrm{C} 367 \mathrm{Y}}$ & + & ND & + & - \\
\hline $\mathrm{pSMV} \mathrm{N}_{\mathrm{T} 341 \mathrm{I}}$ & + & ND & + & - \\
\hline pSMV-N & + & ND & + & - \\
\hline $\mathrm{pSMV}-\mathrm{N}_{\mathrm{G} 319 \mathrm{D}}$ & + & ND & + & - \\
\hline
\end{tabular}

${ }^{a}$ Inoculated plants maintained in a growth chamber $\left(22^{\circ} \mathrm{C}\right)$ were assessed for the presence (+) or absence (-) of the viruses based on symptom expression or reverse-transcriptase polymerase chain reaction assay; ND = not done.

b Plasmids containing full-length infectious cDNAs of the mutants were biolistically delivered into cotyledons or fully expanded primary leaves of soybean seedlings.

c Infectious sap from biolistically inoculated Williams $82(r s v 1)$ was used as inoculum and mechanically inoculated to carborundum-dusted soybean. of the chimeras from Rsvl-genotype soybean. None of the pSMV-N-derived mutants containing only a single mutation in HC-Pro was infectious on Rsvl-genotype soybean; therefore, it is apparent that simultaneous alteration of both $\mathrm{HC}$ Pro and P3 is essential for virulence of pSMV-N on Rsv1genotype soybean.

The initial inoculum used in our studies consisted of molecularly cloned chimeric viruses; therefore, the mutations could not have preexisted in the inoculum. The observation that cDNAs of the chimeras were infectious on Williams 82 ( $r s v l)$ when biolistically delivered but were avirulent on Rsvl-genotype soybean supports this conclusion. Therefore, all mutations leading to adaptations of the progenies to PI 96983 (Rsvl) must have been generated de novo in Williams 82 ( $r s v 1)$ as a result of virus RNA-dependent RNA polymerase error (Drake and Holland 1999; Steinhauer et al. 1992). None of the HC-Pro mutations, however, was detected in the consensus sequences of progenies from William $82(r s v l)$, probably because of their low abundance in the population. The adaptation of the progenies to Rsvl-genotype soybean was associated with a low rate of infection and slow symptom development, which is consistent with the adaptation phenotypes of other plant viruses (Salvador et al. 2008; Wallis et al. 2007). Presumably, variants containing beneficial mutations, with respect to $R s v 1$, represent a small fraction of progenies in a viral population, which leads to a low rate of infection in the inoculated PI 96983 (Rsv1). However, once selected in PI 96983 (Rsvl), such variants quickly reached a sufficient population and became easily detectable in the consensus sequences of the progenies (Fig. 4, compare the sequences of the virus from the first and second passages in PI 96983). Improvement in the rate of infection of progenies passaged in PI 96983 (Rsvl) also suggests an increase in the percentage of variants containing HC-Pro mutations.

Mutations detected in the first passage of progenies in Rsv1genotype soybean were also present in the progenies from subsequent passages, which is indicative of a beneficial impact for the virus (Miralles et al. 1999). Passages of progenies in Rsv1genotype soybean occasionally resulted in accumulation of new mutations in HC-Pro. Possibly, the new mutations are compensatory and reduce the deleterious effect of earlier mutations, as previously shown for HIV drug-resistant mutants (Nijhuis et al. 1999). It is equally possible that the new mutations improved the fitness of progenies in the context of Rsv1genotype soybean. The fact that $\mathrm{pSMV}-\mathrm{N}_{\mathrm{K} 326 \mathrm{E}} / \mathrm{G} 7 \mathrm{P} 3$ was not

Table 2. Responses of soybean genotypes Williams 82 ( $r s v 1)$ and plant introduction (PI) 96983 (Rsv1) to biolistic inoculation with infectious cDNA of chimeras containing a single mutation in helper-component proteinase (HC-Pro $)^{\mathrm{a}}$

\begin{tabular}{|c|c|c|c|}
\hline \multirow[b]{2}{*}{ Chimera } & \multirow[b]{2}{*}{ HC-Pro mutation } & \multicolumn{2}{|c|}{ Soybean genotypes } \\
\hline & & Williams 82 & PI 96983 \\
\hline pSMV-N/G7P3 & $\mathrm{K} 326 \mathrm{E}$ & + & - \\
\hline pSMV-N/G7P3 & W320L & + & + \\
\hline $\mathrm{pSMV-N/G7}{ }_{(2430-3236)}$ & R682G & + & + \\
\hline $\mathrm{pSMV-N/G7} 7_{(2430-3236)}$ & R682K & + & - \\
\hline $\mathrm{pSMV-N/G7}{ }_{(2430-3236)}$ & R318P & + & - \\
\hline $\mathrm{pSMV-N/G7P} 3_{\mathrm{E} 678 \mathrm{G}}$ & F316S & + & + \\
\hline pSMV-N/G7dP3 & V359F & + & + \\
\hline pSMV-N/G7dP3 & $\mathrm{C} 367 \mathrm{Y}$ & + & + \\
\hline $\mathrm{pSMV-N/G7dP} 3_{\mathrm{E} 678 \mathrm{G}}$ & T341I & + & + \\
\hline $\mathrm{pSMV-N/G7d} \mathrm{d}_{(2430-3236)}$ & $\mathrm{F} 317 \mathrm{~S}$ & + & + \\
\hline pSMV-N/G7d ${ }_{(2430-3236)}$ E768G & G319D & + & + \\
\hline
\end{tabular}

a Plasmids containing full-length infectious cDNAs of the chimeras were delivered into expanded primary leaves of soybean seedlings. The inoculated plants were maintained in a growth chamber $\left(22^{\circ} \mathrm{C}\right)$ until evaluated for the presence $(+)$ or absence $(-)$ of infection based on symptom expression and reverse-transcriptase polymerase chain reaction assay. 
virulent when inoculated biolistically to PI 96983 (Rsv1) (Table 2) suggests that K326E does not have the same impact as S353R does in rendering $\mathrm{pSMV-N/G7P3} \mathrm{from} \mathrm{avirulent} \mathrm{to}$ virulent (Fig. 2). This suggests that the secondary mutations are not sufficient for virulence on PI 96983 (Rsvl) and, thus, their role in virulence on $R s v l$-genotype soybean is less significant than the primary mutations.

The HC-Pro and P3 sequences of the progenies were recovered by reverse-transcriptase polymerase chain reaction (RTPCR) amplification, which is a known error-prone process (Bracho et al. 1998). However, because the PCR products, rather than clones of the PCR products, were directly sequenced, most of the nucleotide misincorporation would be expected to be undetectable in the electropherograms. This conclusion is further supported by the following observations: i) no mutations were detected in the HC-Pro cistron of progenies from Williams $82(r s v 1)$, ii) an identical HC-Pro mutation was detected in progenies recovered from different parts of a single infected plant but not from different plants, iii) repeated amplification of the HC-Pro cistron from the same plant revealed identical mutations, iv) mutations detected in HC-Pro of progenies from the first passage were also present in the progenies from subsequent passages in the same soybean genotype, and v) all of the amino acid substitutions in HC-Pro are unique and not shared with SMV strains N, G7, and G7d. More importantly, reconstruction of the HC-Pro mutations in full-length infectious cDNA of chimeric viruses followed by biolistic inoculation to $R s v 1$-genotype soybean resulted in gain of virulence on PI 96983 (Rsv1). This observation demonstrates functional relevance of the HC-Pro mutations to the virulence of chimeric viruses on $R s v 1$-genotype soybean.

The mechanism or mechanisms by which HC-Pro and P3 promote SMV virulence on $R s v 1$-genotype soybean remain to be elucidated. The observation that mutations in HC-Pro are unique among the progenies suggests that P3 influences selection of HC-Pro mutations. It is possible that a polypeptide containing both HC-Pro and P3 acts as the SMV elicitor of Rsv1, assuming that Rsv1-mediated recognition of SMV-N involves direct interaction with the SMV elicitor. The single ORF of SMV is expressed as a precursor polypeptide, which is subsequently cleaved co-translationally and post-translationally by three virus-encoded proteases (Hull 2002; Jayaram et al. 1992). Thus, it is likely that, at any given time, $P 3$ exists in different polypeptide contexts within infected cells, as shown for the Potyvirus Tobacco mottle virus (Rodríguez-Cerezo and Shaw 1991). However, one cannot exclude the possibility that a functional redundancy of HC-Pro and P3 (Urcuqui-Inchima et al. 2001) is involved. It has been suggested that overcoming $R$-mediated defense responses of a host by an invading virus is determined by the speed at which the virus can replicate and move cell to cell compared with the speed by which the host defense system can act (Culver et al. 1991). It is equally possible that P3 acts as the elicitor but HC-Pro is serving as a suppressor of $R s v 1$-mediated defense responses (Alamillo et al. 2006). The HC-Pro is known to play a multifunctional role in the life cycle of potyviruses, including genome amplification and cell-to-cell and systemic movement. Furthermore, it is a strong suppressor of gene silencing (Urcuqui-Inchima et al. 2001). On the other hand, P3 is also believed to be involved in cell-to-cell movement and virus replication (Urcuqui-Inchima et al. 2001). Interestingly, all of the HC-Pro mutations associated with adaptations of the pSMV-N-derived P3 chimeras are located in $\mathrm{N}$ - and $\mathrm{C}$-terminal domains. These domains are involved in HC-Pro self-interaction and virus movement, respectively (Urcuqui-Inchima et al. 2001). All of the substitutions essential for virulence of the chimeric viruses on PI $96983(R s v 1)$ (Table 2) have the potential to alter the tertiary structure or overall net charge of HC-Pro. This suggests that, in the context of Rsvl-genotype soybean, change in HC-Pro structure or polarity is essential to the results observed. The observation that $\mathrm{SMV}-\mathrm{N}_{\mathrm{R} 682 \mathrm{~K}} / \mathrm{G}_{(2430-3236)}$ was not virulent on Rsv1-genotype soybean (Table 2) supports this conclusion because an arginine to lysine substitution likely has minimal or no impact on tertiary structure of HC-Pro.

Involvement of two cistrons of a Potyvirus sp. in overcoming an $R$-mediated resistance response is unusual among nonpotyviruses. In the two well-studied ER-expressing pathosystems involving the Tobamovirus Tomato mosaic virus (ToMV) (ToMV/Tm-1, ToMV/Tm-2, and ToMV/Tm- $2^{2}$ ) and the Potexvirus Potato virus $X / R x$, only a single viral gene acts as the elicitor (Culver 1997; Meshi et al. 1988, 1989; Weber et al. 1993). However, among Potyvirus spp., involvement of more than one cistron in interaction with an $R$-genotype plant has been reported, but this was attributed to the existence of two independent $R$ genes against the virus (Jenner et al. 2002). However, with regard to the SMV/Rsv1 pathosystem, classical genetic studies on PI 96983 (Rsvl) by independent research groups all point to the presence of a single $R$ gene against SMV (Chen et al. 1991, 1994; Kiihl and Hartwig 1979). Furthermore, high-resolution mapping has provided evidence that a single gene from PI 96983 (Rsvl) was associated with the Rsv1 phenotype against SMV (Hayes et al. 2004). Nevertheless, one cannot exclude the possibility of additional $R$ genes in a very tightly linked gene cluster containing Rsvl (Hayes et al. 2004).

The observation that adaptations of progenies from pSMVN-derived P3 chimeras to L78-379 (Rsvl), a near isoline of Williams ( $r s v 1)$ with the Rsvl allele derived from line PI 96983 (Bernard et al. 1991), requires an additional mutation in HC-Pro compared with the adaptation to PI 96983 (Rsv1), is surprising. The differential responses between PI 96983 (Rsvl) and L78-379 $(R s v 1)$ to inoculation with pSMV-G7 and a pSMV-G7-derived P3-chimeric virus also was observed previously (Hajimorad et al. 2003, 2005). One expects that Rsv1 imposes a similar pressure on pSMV-N-derived P3 chimeras regardless of the soybean genetic context. However, it has been shown recently that the effectiveness of the $R$ genes is influenced by host genetic background (Saghai Maroof et al. 2008).

We have now established that P3 of SMV-G7 and SMV-N elicit Rsv1-mediated LSHR and ER, respectively (Hajimorad et al. 2005, 2006), and that virulence of SMV-N on Rsvl-genotype soybean requires HC-Pro complementation of P3. However, the relationship between HC-Pro and P3 as well as the individual functional role of each of the two cistrons in interaction with $R s v 1$-genotype soybean remains to be understood. It is worth mentioning that Rsvl-mediated elicitor functions of SMV have been demonstrated so far in the context of virus replication only. This is in contrast to Tobamovirus and Potexvirus pathosystems where $R$-mediated elicitor function for a number of viral genes has been established in the context of replication as well as dissociated from replication through transient gene expression (Hull 2002).

In conclusion, we used an experimental evolutionary approach and identified HC-Pro as the second cistron involved in virulence of pSMV-N on Rsvl-genotype soybean and identified multiple substitutions crucial for virulence. Eggenberger and associates (2008) recently applied a comparative approach and, through construction of a series of chimeras and sitedirected mutants between SMV-N and SMV-G7 and analyses on L78-379 (Rsv1), concluded that concurrent substitutions of one amino acid in the HC-Pro (R682M) and two in P3 is sufficient for virulence of SMV-N. Interestingly, in this study, we also identified a substitution at amino acid 682 as sufficient for 
virulence of $\mathrm{pSMV-N/G7} 7_{(2430-3236)}$ on PI 96983 (Rsv1); however, in our study, the replacement involved glycine instead of methionine. Methionine and glycine are both hydrophobic and their replacement for arginine has a similar impact. The identification of R682G by our method demonstrates the potential of evolutionary experiments as another approach to the comparative studies of strains in mapping virulent determinants of plant viruses. Our success shows that evolutionary experiments (Elena and Lenski 2003) provide an alternative approach to reveal virulence determinants of viruses in pathosystems which are not amenable to comparative study because of the absence of a naturally occurring resistance-breaking strain of the virus that is involved. One such pathosystem involves $\mathrm{Po}$ tato virus $Y$ and the $R y$ gene from potato (Mestre et al. 2000). This may further enhance potential for understanding mechanisms of virus virulence, which is an important component of future development of disease control through deployment of resistant crop plants.

As was discussed elsewhere (Hajimorad et al. 2003), the results of studies on experimental adaptation of viruses in the laboratory must be interpreted with caution in regard to the durability of $R$ genes. Here, we adapted avirulent chimeras derived from SMV-N that contained precise or partial P3 sequences from two virulent strains by mechanical inoculation and high population transfer that is known to favor selection of novel mutants with the highest relative fitness (Clarke et al. 1993; Novella et al. 1995). The data clearly demonstrate that two cistrons of SMV-N are involved in virulence of the virus on Rsv1genotype soybean. Eggenberger and associates (2008) have also reached a similar conclusion but through comparative studies between SMV-N and SMV-G7. Based on these observations, one may predict that, because of requirement for mutations in two different virus cistrons simultaneously, overcoming $R s v 1$-mediated resistance by SMV-N under the natural conditions is not easy. However, such a prediction would be accurate if adaptation of nonmodified SMV-N to Rsvl-genotype soybean reveals a similar requirement. Currently, a series of evolutionary experiments are underway to adapt nonmodified SMV-N to Rsvl-genotype soybean.

\section{MATERIALS AND METHODS}

\section{Viruses, soybean genotypes, inoculation, and SMV detection.}

Plasmids containing infectious full-length cDNA clones of SMV-G7 (pSMV-G7), SMV-G7d (pSMV-G7d), SMV-N (pSMV-N), and pSMV-N ${ }_{\mathrm{V} 822 \mathrm{M}+\mathrm{K} 952 \mathrm{E}+\mathrm{A} 1111 \mathrm{~V}}$, and pSMV-Nderived P3 chimeras containing the full-length or the N-terminus P3 from pSMV-G7 or pSMV-G7d (pSMV-N/G7P3, pSMV-

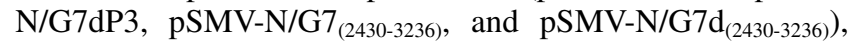
have been previously described (Hajimorad et al. 2003, 2006; Wang et al. 2006). The plasmids were propagated in ElectroMax DH5 $\alpha$-E (Invitrogen, Carlsbad, CA, U.S.A.) and purified by using a QiaPrep Spin MiniPrep Kit (Qiagen, Valencia, CA, U.S.A.). The soybean (Glycine max) cv. Williams 82 (rsvl) (Bernard and Cremeens 1988), susceptible to all strains of SMV; line PI 96983 (Rsv1) (Kiihl and Hartwig 1979); and line L78-379 (Rsv1) (Buzzell and Tu 1984), a near isoline of Williams (Bernard and Lindahl 1972) with the Rsv1 allele derived from line PI 96983 (Williams [6] × PI 96983) (Bernard et al. 1991), were used in this study. All seed were obtained from plants shown to be free of SMV by indexing. To establish infection, plasmid DNA was biolistically inoculated to hypocotyls or expanded primary leaves of soybean seedlings. Sap containing viral progenies from the infected plants was used to mechanically inoculate carborundum (600 mesh)-dusted soybean (Hajimorad and Hill 2001). The inoculated plants were maintained in a growth chamber operating at $22^{\circ} \mathrm{C}$ with a photoperiod of $16 \mathrm{~h}$. The SMV detection was done by squash immunoblotting, double-antibody sandwich enzyme-linked immunosorbent assay, or RT-PCR (Hajimorad and Hill 2001).

\section{Site-directed mutagenesis.}

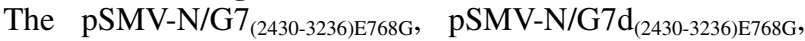
and $\mathrm{pSMV-N} / \mathrm{G} 7_{(2430-3236) \mathrm{E} 768 \mathrm{G}+\mathrm{V} 996 \mathrm{~A}}$ originated during PCR synthesis of chimeras (Hajimorad et al. 2006) due to nucleotide misincorporation by the LA Taq polymerase (Takara Bio, Madison, WI, U.S.A.) that was used. A KpnI/SpeI fragment from each of these plasmids was released and ligated into similarly digested pSMV-N/G7P3 or pSMV-N/G7dP3

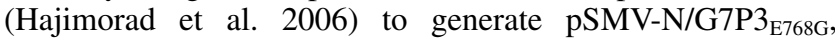
pSMV-N/G7dP3 $3_{\mathrm{E} 768 \mathrm{G}}$, and pSMV-N/G7P3 $3_{\mathrm{E} 768 \mathrm{G}+\mathrm{V} 996 \mathrm{~A}}$.

To introduce intended point mutations into $\mathrm{P} 3$, megaprimer PCR-based mutagenesis was used (Sambrook and Russell 2001), utilizing the appropriate restriction sites (Fig. 1). The genomic positions for these restriction sites on SMV-N differ from those of SMV-G7 and SMV-G7d by three nucleotides, because SMV-N lacks a codon relative to SMV-G7 and SMVG7d in the P1 region. Point mutations were constructed by performing an initial PCR with the mutagenic primer and a primer $5^{\prime}$ of the region to be cloned. That PCR product then was used as a megaprimer in a PCR with a primer $3^{\prime}$ of the region to be cloned. PCR for constructing point mutations was performed using LA Taq DNA polymerase (Takara Bio). The details of creating P3 point mutants are presented in Supplementary Materials and Methods.

Site-directed mutagenesis of the pSMV-N HC-Pro cistron was done similarly. However, due to a lack of unique restriction sites near the $5^{\prime}$ end of the SMV-N HC-Pro, two intermediate plasmids were constructed. To generate the first intermediate plasmid, a NotI/BamHI fragment, consisting of the $35 \mathrm{~S}$ promoter and the $5^{\prime} 2.3-\mathrm{kb}$ of the SMV-N cDNA, was first cloned into pBR322-35S (Wang et al. 2006) that had been similarly digested. The BstXI and ApaI sites at nucleotides 345 and 1,306 , respectively, of SMV-N were unique in this subclone. The plasmid then was digested with Bst XI and ApaI and the restriction fragment was replaced with a synthetic BstXI/ApaI adaptor. The second intermediate plasmid was constructed by digesting pSMV-N with NotI and BglII to release a fragment consisting of the $35 \mathrm{~S}$ promoter and $5^{\prime} 1.6 \mathrm{~kb}$ of the SMV-N cDNA, and replacing that fragment with a synthetic NotI/BglII adaptor.

To construct pSMV-N-derived P3 chimeras containing a single mutation in HC-Pro, KpnI/SpeI or KpnI/SalI fragments were released from the chimeras and ligated into a similarly digested pSMV-N-derived HC-Pro mutant containing the desired mutation. To construct pSMV-N ${ }_{\mathrm{W} 320 \mathrm{~L}} / \mathrm{G} 7 \mathrm{P} 3$ and $\mathrm{pSMV}$ $\mathrm{N}_{\mathrm{K} 326 \mathrm{E}} / \mathrm{G} 7 \mathrm{P} 3$, a KpnI/Sal1 fragment was released from $\mathrm{pSMV}$ N/G7P3 (Hajimorad et al. 2006) and ligated into similarly digested pSMV-N $\mathrm{W}_{320 \mathrm{~L}}$ and pSMV-N $\mathrm{K}_{\mathrm{K} 326 \mathrm{E}}$, respectively. To construct pSMV-N ${ }_{\mathrm{V} 359 \mathrm{~F}} / \mathrm{G} 7 \mathrm{dP} 3$ and pSMV-N ${ }_{\mathrm{C} 367 \mathrm{Y}} / \mathrm{G} 7 \mathrm{dP} 3$, a KpnI/ SalI fragment was released from pSMV-N/G7dP3 (Hajimorad et al. 2006) and ligated into similarly digested $\mathrm{pSMV}_{\mathrm{V}} \mathrm{N}_{\mathrm{V} 359 \mathrm{~F}}$

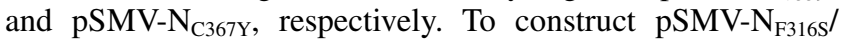
$\mathrm{G} 7 \mathrm{P} 3_{\mathrm{E} 768 \mathrm{G}}$ and $\mathrm{pSMV}-\mathrm{N}_{\mathrm{T} 341 \mathrm{I}} / \mathrm{G} 7 \mathrm{dP} 3_{\mathrm{E} 768 \mathrm{G}}$, a KpnI/SalI fragment

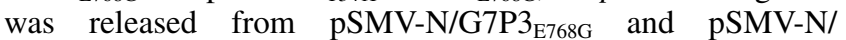
$\mathrm{G} 7 \mathrm{dP} 3_{\mathrm{E} 768 \mathrm{G}}$ and ligated into similarly digested $\mathrm{pSMV}-\mathrm{N}_{\mathrm{F} 316 \mathrm{~S}}$ and $\mathrm{pSMV}-\mathrm{N}_{\mathrm{T} 341 \mathrm{I}}$, respectively. To construct $\mathrm{pSMV}-\mathrm{N}_{\mathrm{R} 682 \mathrm{G}} /$

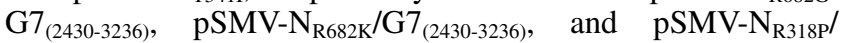
G7 (2430-3236), a KpnI/SpeI fragment was released from pSMV-N/ G7 (2430-3236) (Hajimorad et al. 2006) and ligated into similarly digested pSMV- $\mathrm{N}_{\mathrm{R} 682 \mathrm{G}}$, and $\mathrm{pSMV}-\mathrm{N}_{\mathrm{R} 682 \mathrm{~K}}$, and $\mathrm{pSMV}-\mathrm{N}_{\mathrm{R} 318 \mathrm{P}}$, respectively. To construct $\mathrm{pSMV}-\mathrm{N}_{\mathrm{F} 317 \mathrm{~S}} / \mathrm{G} \mathrm{d}_{(2430-3236)}$ a $\mathrm{KpnI} / \mathrm{SpeI}$ fragment was released from $\mathrm{pSMV-N} / \mathrm{G} 7 \mathrm{~d}_{(2430-3236)}$ (Hajimorad 
et al. 2006) and ligated into similarly digested pSMV- $\mathrm{N}_{\mathrm{F} 317 \mathrm{~s}}$. To construct pSMV-N $\mathrm{N}_{\mathrm{G} 319 \mathrm{D}} / \mathrm{G} \mathrm{d}_{(2430-3236) \mathrm{E} 768 \mathrm{G}}$, a KpnI/SpeI fragment was released from $\mathrm{pSMV-N} / \mathrm{G} 7 \mathrm{~d}_{(2430-3236) \mathrm{E} 768 \mathrm{G}}$ and ligated into similarly digested $\mathrm{pSMV}-\mathrm{N}_{\mathrm{G} 319 \mathrm{D}}$. The identity of all the resultant plasmids were confirmed by sequencing that targeted the HC-Pro sequences containing the point mutations and chimeric P3 regions. The oligonucleotides used for the synthesis of point mutants, RT-PCR, and sequencing are listed in Supplementary Table S1.

\section{RT-PCR and sequencing.}

Total RNA from soybean was isolated from systemically infected fresh leaves or liquid nitrogen-frozen soybean tissues kept at $-85^{\circ} \mathrm{C}$ by using an RNeasy Plant Mini Kit (Qiagen). The genomic regions of progeny viruses were reverse transcribed by using SuperScript reverse transcriptase (Invitrogen) and an SMV-specific primer downstream of the P3 cistron. PCR amplification of progeny viruses was done using Ex Taq polymerase (Takara Bio). The resultant PCR products were purified by using a QIAquick-PCR purification kit (Qiagen) and subsequently used as templates in nested PCRs. These PCR products were purified and sequenced. Sequencing was done at the University of Tennessee or Iowa State University DNA Sequencing Facilities. The sequences were edited by Factura (Applied Biosystems, Foster City, CA, U.S.A.) and analyzed using AutoAssembler DNA sequence assembly software (Applied Biosystems).

\section{ACKNOWLEDGMENTS}

This project was supported in part by the University of Tennessee College of Agriculture and Experimental Station, the Iowa State University College of Agriculture and Experimental Station, the North Central Soybean Research Program, and by the Iowa Soybean Association. We thank M. Mazarei (University of Tennessee) for critical reading of the manuscript.

\section{LITERATURE CITED}

Abramovitch, R. B., Kim, Y.-J., Chen, S., Dickman, M. B., and Martin, G. B. 2003. Pseudomonas type III effector AvrPtoB induces plant disease susceptibility by inhibition of host programmed cell death. EMBO (Eur. Mol. Biol. Organ.) J. 22:60-69.

Alamillo, J. M., Saénz, P., and García, J. A. 2006. Salicylic acid-mediated and RNA-silencing defense mechanisms cooperate in the restriction of systemic spread of Plum pox virus in tobacco. Plant J. 48:217-227.

Bendahmane, A., Kanyuka, K., and Baulcombe, D. C. 1999. The $R x$ gene from potato controls separate virus resistance and cell death responses. Plant Cell 11:781-791.

Bernard, R. L., and Cremeens, C. R. 1988. Registration of "Williams 82" soybean. Crop Sci. 28:1027-1028.

Bernard, R. L., and Lindahl, D. A. 1972. Registration of Williams soybean. Crop Sci. 12:716

Bernard, R. L., Nelson, R. L., and Cremeens, C. R. 1991. USDA soybean genetic collection: Isoline collection. Soybean Genet. Newsl. 18:27-57.

Bonas, U., and Lahaya, T. 2002. Plant disease resistance triggered by pathogen-derived molecules: Refined models of specific recognition. Curr. Opin. Microbiol. 5:44-50.

Bracho, M. A., Moya, A., and Barrio, E. 1998. Contribution of Taq polymerase-induced errors to the estimation of RNA virus diversity. J. Gen. Virol. 79:2921-2928.

Buzzell, R. I., and Tu, J. C. 1984. Inheritance of soybean resistance to soybean mosaic virus. J. Hered. 75:82.

Chen, P., Buss, G. R., Roane, C. W., and Tolin, S. A. 1991. Allelism among genes for resistance to soybean mosaic virus in strain-differential soybean cultivars. Crop Sci. 31:305-309.

Chen, P., Buss, G. R., Roane, C. W., and Tolin, S. A. 1994. Inheritance in soybean of resistant and necrotic reactions to soybean mosaic virus strains. Crop Sci. 34:414-422.

Cho, E.-K., and Goodman, R. M. 1979. Strains of soybean mosaic virus: Classification based on virulence in resistant soybean cultivars. Phytopathology 69:467-470.

Clarke, D. K., Duarte, E. A., Moya, A., Elena, S. F., Domingo, E., and Holland, J. 1993. Genetic bottlenecks and population passages cause profound fitness differences in RNA viruses. J. Virol. 67:222-228.

Culver, J. N. 1997. Viral avirulence genes. Pages 196-219 in: PlantMicrobe Interactions, Vol. 2. G. Stacey and N. T. Keen, eds. Chapman \& Hall, New York.

Culver, J. N., Lindbeck, A. G. C., and Dawson, W. O. 1991. Virus-host interactions: Induction of chlorotic and necrotic responses in plants by tobamoviruses. Annu. Rev. Phytopathol. 29:193-217.

Dangl, J. L., and Jones, J. D. G. 2001. Plant pathogens and integrated defense responses to infection. Nature 411:826-833.

Diveki, Z., Salanki, K., and Balazs, E. 2004. The necrotic pathotype of the Cucumber mosaic virus (CMV) Ns strain is solely determined by amino acid 461 of the 1a protein. Mol. Plant-Microbe Interact. 17:837845.

Drake, J. W., and Holland, H. 1999. Mutation rates among RNA viruses. Proc. Natl. Acad. Sci. U.S.A. 96:13910-13913.

Eggenberger, A. L., Hajimorad, M. R., and Hill, J. H. 2008. Gain of virulence on Rsv1-genotype soybean by an avirulent Soybean mosaic virus requires concurrent mutations in both P3 and HC-Pro. Mol. PlantMicrobe Interact. 21:931-936.

Elena, S. F., and Lenski, R. E. 2003. Evolution experiments with microorganisms: The dynamics and genetic bases of adaptation. Nat. Rev. Genet. 4:457-469.

Flor, H. H. 1971. Current status of the gene-for-gene concept. Annu. Rev. Phytopathol. 9:275-296.

García-Arenal, F., Fraile, A., and Malpica, J. M. 2001. Variability and genetic structure of plant virus populations. Annu. Rev. Phytopathol. 39:157-186.

Hajimorad, M. R., and Hill, J. H. 2001. Rsv1-mediated resistance against Soybean mosaic virus $-\mathrm{N}$ is hypersensitive response-independent at inoculation site, but has the potential to initiate a hypersensitive response-like mechanism. Mol. Plant-Microbe Interact. 14:587598.

Hajimorad, M. R., Eggenberger, A. L., and Hill, J. H. 2003. Evolution of Soybean mosaic virus-G7 molecularly cloned genome in Rsvl-genotype soybean results in emergence of a mutant capable of evading Rsv1-mediated recognition. Virology 314:497-509.

Hajimorad, M. R., Eggenberger, A. L., and Hill, J. H. 2005. Loss and gain of elicitor function of Soybean mosaic virus G7 provoking Rsv1-mediated lethal systemic hypersensitive response maps to P3. J. Virol. 79:1215-1222.

Hajimorad, M. R., Eggenberger, A. L., and Hill, J. H. 2006. Strain-specific P3 of Soybean mosaic virus elicits Rsv1-mediated extreme resistance, but absence of $\mathrm{P} 3$ elicitor function alone is insufficient for virulence on Rsv1-genotype soybean. Virology 345:156-166.

Hayes, A. J., Jeong, S. C., Gore, M. A., Yu, Y. G., Buss, G. R., Tolin, S. A., and Saghai Maroof, M. A. 2004. Recombination within a nucleotidebinding-site/leucine-rich-repeat gene cluster produces new variants conditioning resistance to Soybean mosaic virus in soybeans. Genetics 166:493-503.

Hull, R. 2002. Matthew's Plant Virology. Academic Press, New York.

Jackson, R. W., Athanassopoulos, E., Tsiamis, G., Mansfield, J. W., Sesma, A., Arnold, D. L., Gibbon, M. J., Murillo, J., Taylor, J. D., and Vivian, A. 1999. Identification of a pathogenicity island, which contains genes for virulence and avirulence, on a large native plasmid in the bean pathogen Pseudomonas syringae pathovar phaseolicola. Proc. Natl. Acad. Sci. U.S.A. 96:10875-10880.

Jayaram, C. H., Hill, J. H., and Miller, W. A. 1992. Complete nucleotide sequences of two Soybean Mosaic Virus strains differentiated by response of soybean containing the Rsv resistance gene. J. Gen. Virol. 73:2067-2077.

Jenner, C. E., Tomimura, K., Ohshima, K., Hughes, S. L., and Walsh, J. A. 2002. Mutations in Turnip mosaic virus $\mathrm{P} 3$ and cylindrical inclusion proteins are separately required to overcome two Brassica napus resistance genes. Virology 300:50-59.

Jenner, C. E., Wang, X., Tomimura, K., Ohshima, K., Ponz, F., and Walsh, J. A. 2003. The dual role of the potyvirus P3 protein of Turnip mosaic virus as a symptom and avirulence determinant in Brassicas. Mol. Plant-Microbe Interact. 16:777-784.

Karasawa, A., Okada, I., Akashi, K., Chida, Y., Hase, S., Nakazawa-Nasu, Y., Ito, A., and Ehara, Y. 1999. One amino acid change in cucumber mosaic virus RNA polymerase determines virulent/avirulent phenotypes on cowpea. Phytopathology 89:1186-1192.

Kiihl, R. A. S., and Hartwig, E. E. 1979. Inheritance of reaction to soybean mosaic virus in soybeans. Crop Sci. 19:372-375.

Kim, C.-H., and Palukaitis, P. 1997. The plant defense response to cucumber mosaic virus in cowpea is elicited by the viral polymerase gene and affects virus accumulation in single cells. EMBO (Eur. Mol. Biol. Organ.) J. 16:4060-4068.

Kiraly, L., Cole, A. B., Bourque, J. E., and Schoelz, J. E. 1999. Systemic cell death is elicited by the interaction of a single gene in Nicotiana 
clevelandii and gene VI of Cauliflower mosaic virus. Mol. PlantMicrobe Interact. 12:919-925.

Leach, J. E., Vera Cruz, C. M., Bai, J., and Leung, H. 2001. Pathogen fitness penalty as a predictor of durability of disease resistance genes. Annu. Rev. Phytopathol. 39:187-224.

Lim, S. M. 1985. Resistance to soybean mosaic virus in soybeans. Phytopathology 75:199-201.

Malcuit, I., Marano, M. R., Kavanagh, T. A., De Jong, W., Forsyth, A., and Baulcombe, D. C. 1999. The 25-kDa movement protein of PVX elicits $\mathrm{Nb}$-mediated hypersensitive cell death in potato. Mol. Plant-Microbe Interact. 6:536-543.

Maule, A. J., Caranta, C., and Boulton, M. I. 2007. Sources of natural resistance to plant viruses: Status and prospects. Mol. Plant Pathol. 8:223231.

Meshi, T., Motoyoshi, F., Adachi, A., Watanabe, Y., Takamatsu, N., and Okada, Y. 1988. Two concomitant base substitutions in the putative replicase genes of tobacco mosaic virus confer the ability to overcome the effects of a tomato resistance gene, Tm-1. EMBO (Eur. Mol. Biol. Organ.) J. 7:1575-1581.

Meshi, T., Motoyoshi, F., Maeda, T., Yoshiwoka, S., Watanabe, H., and Okada, Y. 1989. Mutations in the tobacco mosaic virus $30-\mathrm{kD}$ protein gene overcome Tm-2 resistance in tomato. Plant Cell 1:515-522.

Mestre P., Brigneti, G., and Baulcombe, D. C. 2000. An Ry-mediated resistance response in potato requires the intact active site of the NIa proteinase from Potato virus Y. Plant J. 23:653-661.

Miralles, R., Gerrish, P. J., Moya, A., and Elena, S. F. 1999. Clonal interference and the evolution of RNA viruses. Science 285:1745-1747.

Nijhuis, M., Schuurman, R., de Jong, D., Erickson, J., Gustchina, E., Albert, J., Schipper, P., Gulnik, S., and Boucher, C. A. B. 1999. Increased fitness of drug resistant HIV-I protease as a result of acquisition of compensatory mutations during sub-optimal therapy. AIDS 13:2349-2359.

Novella, I. S., Duarte, E. A., Elena, S. F., Moya, A., Domingo, E., and Holland, J. J. 1995. Exponential increases of RNA virus fitness during large population transmissions. Proc. Natl. Acad. Sci. U.S.A. 92:58415844

Padgett, H. S., Watanabe, Y., and Beachy, R. N. 1997. Identification of the TMV replicase sequence that activates the $\mathrm{N}$ gene-mediated hypersensitive response. Mol. Plant-Microbe Interact. 10:709-715.

Rodríguez-Cerezo, E., and Shaw, J. G. 1991. Two newly detected non- structural viral proteins in potyvirus-infected cells. Virology 185:572-579.

Saghai Maroof, M. A., Jeong, S. C., Gunduz, I., Tucker, D. M., Buss, G. R., and Tolin, S. A. 2008. Pyramiding of Soybean mosaic virus resistance genes by marker-assisted selection. Crop Sci. 48:517-526.

Salvador, B., Delgadillo, M. O., Saénz, P., García, J. A., and Simón-Mateo, C. 2008. Identification of Plum pox virus pathogenicity determinants in herbaceous and woody hosts. Mol. Plant-Microbe Interact. 21:20-29.

Sambrook, J., and Russell, D. W. 2001. Molecular Cloning: A Laboratory Manual, 3rd ed. Cold Spring Harbor Laboratory Press, Cold Spring Harbor, NY, U.S.A

Stahl, E. A., and Bishop, J. B. 2000. Plant-pathogen arms races at the molecular level. Curr. Opin. Plant Biol. 3:299-304.

Steinhauer, D. A., Domingo, E., and Holland, J. J. 1992. Lack of evidence for proofreading mechanisms associated with an RNA virus polymerase. Gene 122:281-288.

Tsiamis, G., Mansfield, J. W., Hockenhull, R., Jackson, R. W., Sesma, A., Athanassopoulos, E., Bennett, M. A., Stevens, C., Vivian, A., Taylor, J. D., and Murillo, J. 2000. Cultivar-specific avirulence and virulence functions assigned to avrPphF in Pseudomonas syringae pv. phaseolicola, the cause of bean halo-blight disease. EMBO (Eur. Mol. Biol. Organ.) J. 19:3204-3214.

Tsuda, S., Kirita, M., and Watanabe, Y. 1998. Characterization of a pepper mild mottle tobamovirus strain capable of overcoming the L3 genemediated resistance, distinct from the resistance-breaking Italian isolate. Mol. Plant Microbe Interact 11:327-331.

Urcuqui-Inchima, S., Haenni, A.-L. and Bernardi, F. 2001. Potyvirus proteins: A wealth of functions. Virus Res. 74:157-175.

Wallis, C. M., Stone, A. L., Sherman, D. J., Damsteegt, V. D., Gildow, F. E., and Schneider, W. L. 2007. Adaptation of plum pox virus to a herbaceous host (Pisum sativum) following serial passages. J. Gen. Virol. 88:2839-2845.

Wang, L., Eggenberger, A., Hill, J., and Bogdanove, A. J. 2006. Pseudomonas syringae effector $A v r B$ confers soybean cultivar-specific avirulence on Soybean mosaic virus adapted for transgene expression but effector AvrPto does not. Mol. Plant-Microbe Interact. 19:304-312.

Weber, H., Schultze, S., and Pfitzner, A. J. P. 1993. Two amino acid substitutions in the tomato mosaic virus 30 -kilodalton movement protein confer the ability to overcome the $T m-2^{2}$ resistance gene in the tomato. J. Virol. 67:6432-6438. 